\title{
Climate variability recorded in tropical and sub-tropical
}

speleothems

Judson W. Partin' ${ }^{1}$, K.M. CobB ${ }^{2}$ And J.L. Banner ${ }^{1}$

'Jackson School of Geosciences, University of Texas at Austin, USA; jpartin@mail.utexas.edu 2Department of Earth and Atmospheric Sciences, Georgia Institute of Technology, Atlanta, USA

Speleothems provide records that fill an important gap in knowledge about past terrestrial environmental conditions. They complement paleoclimate records from marine/lacustrine sediments, corals and ice cores by supplying additional information about hydrologic variability on land from a wide array of karst settings, ranging from the deep tropics to the Alps. The combination of precipitation and temperature paleoclimate records help to describe the mechanisms of climate changes, and can be used as targets for global climate models run with different climatic forcings.

Speleothems have several advantages as paleo-proxies that make them well-suited to the study of past terrestrial climates. First, speleothems form in caves, which are ubiquitous on all continents, including the tropics, where ice cores are rare. Second, the uranium-decay series provides the means to measure absolute ages on speleothems as old as $\sim 600$ kyrs with relative errors of $\sim 0.5-1 \%$ (Edwards et al., 1987; Cheng et al., 2000). Third, several different proxies (some geochemical and some morphological) can be used to probe patterns of past hydrological variability. Fourth, average growth rates of $\sim 10-100 \mu \mathrm{m} / \mathrm{yr}$ yield decadally resolved proxy records, although in some cases faster growing speleothems allow for the generation of sub-annually resolved records (Treble et al., 2003; Johnson et al., 2006). Lastly, speleothems form over many millennia, yielding long records of hydrologic variability. These attributes mean that long high-resolution records can be obtained from areas, such as the tropics, which are poorly resolved by other paleoclimate archives.

There are many proxies that have been successfully applied in speleothems, including oxygen isotopic composition $\left(\delta^{18} \mathrm{O}\right)$, carbon isotopic composition $\left(\delta^{13} \mathrm{C}\right)$, trace metal ratio (i.e., $\mathrm{Mg} / \mathrm{Ca}$ ), and growth rate/annual band thickness. Arguably, the most robust proxy in speleothems is carbonate $\delta^{18} \mathrm{O}$, which tracks rainfall $\delta^{18} \mathrm{O}$ variability at the site assuming equilibrium carbonate precipitation (although see Mickler et al., 2004 for a discussion of disequilibrium effects). Rainfall $\delta^{18} \mathrm{O}$ variability is driven by large-scale evaporation, precipitation, and circulation patterns. To a first approximation, rainfall $\delta^{18} \mathrm{O}$ is correlated to temperature at high-latitude sites, and anti-correlated to precipitation

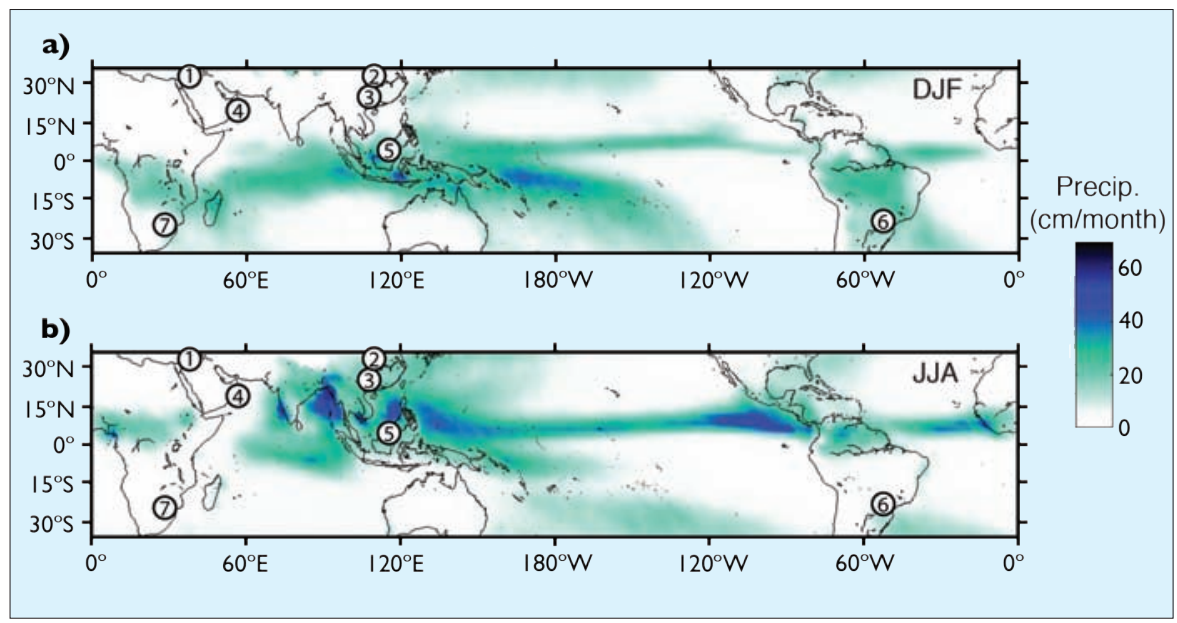

Figure 1: Austral (a) and boreal (b) summer precipitation ( $\mathrm{cm} / \mathrm{month})$, where the values represent an average over the months of December, January, and February (DJF) and June, July, and August (JJA) respectively. Numbers indicate the geographical location of Holocene speleothem records plotted in Figure 2. 1) Sorea Cave, Israel (BarMatthews et al., 2003); 2) Heshang Cave, China; (Hu et al., 2008); 3) Dongge (ave, China (Wang et al., 2005); 4) Qunf Cave, Oman (Fleitmann et al., 2003); 5) Snail Shell and Bukit Assam Caves, N. Borneo (Partin et al., 2007); 6) Botuverá Cave, Brazil (Wang et al., 2006); 7) Cold Air Cave, S. Africa (Holmgren et al., 2003).

amount at tropical sites. In the tropics and sub-tropics, the empirical, inverse relationship between rainfall amount and rainfall $\delta^{18} \mathrm{O}$ is called the "amount effect" (Dansgaard, 1964; Rozanski et al., 1993). Efforts to calibrate speleothem proxies, including $\delta^{18} \mathrm{O}$, to instrumental climate data have identified key environmental controls on speleothem proxy composition, such as rainfall amount, rainfall source, and temperature.

An excellent example of a speleothembased map of the paleo-hydrologic cycle comes from the last $10 \mathrm{kyr}$, when precessional insolation forcing dominated. At the beginning of the Holocene ( 10 kyr), boreal summer insolation was at a relative maximum and austral summer insolation was at a relative minimum. Over the course of the Holocene, the strengths of the summer seasons in each hemisphere reversed, such that boreal summer insolation is presently at a relative minimum and austral summer insolation is at a relative maximum.

Speleothem records prove that these changes in summer insolation impacted the strength and position of deep convection throughout the tropics (seasonal extremes of which are shown in Fig. 1). These speleothem records exhibit sensitivity to changes in the strength and/or position of the large-scale atmospheric circulations associated with monsoonal troughs and/ or the Intertropical Convergence Zone (ITCZ). In all cases, the speleothem records suggest that summer insolation forcing is one of the most important drivers for tropical hydrological variability over the Holocene (Fig. 2). For example, locations in both Oman (Fleitmann et al., 2003) and China (Wang et al., 2005; Hu et al., 2008) lie near the northern limit of the IndianAsian Monsoon system, and speleothem records from these sites display an early Holocene minimum in $\delta^{18} \mathrm{O}$ (interpreted as a maximum in rainfall). As a result, these precipitation records display a maximum in precipitation during the early Holocene when boreal summer insolation was at a maximum (Fig. 2). An early Holocene precipitation maximum is even present in the Mediterranean climate of Israel (BarMatthews et al., 2003), suggesting that summers there may have been wetter 10 kyr ago (Fig. 2).

Alternatively, speleothem records from Brazil (Wang et al., 2006) and South Africa (Holmgren et al., 2003), which lie at the southern edge of monsoonal circulation regimes in the southern hemisphere, are consistent with early Holocene minima in rainfall (Fig. 2). The wettest part of the record occurs during the late Holocene, consistent with austral summer insolation increasing through the Holocene (Fig. 2).

The records from northern Borneo (Partin et al., 2007) display a mid-Holocene maximum that is consistent with its location at the fulcrum of the northern and southern hemisphere monsoonal circulations. The records from Borneo highlight the complex hydrological response of locations in the deep tropics to seasonal 


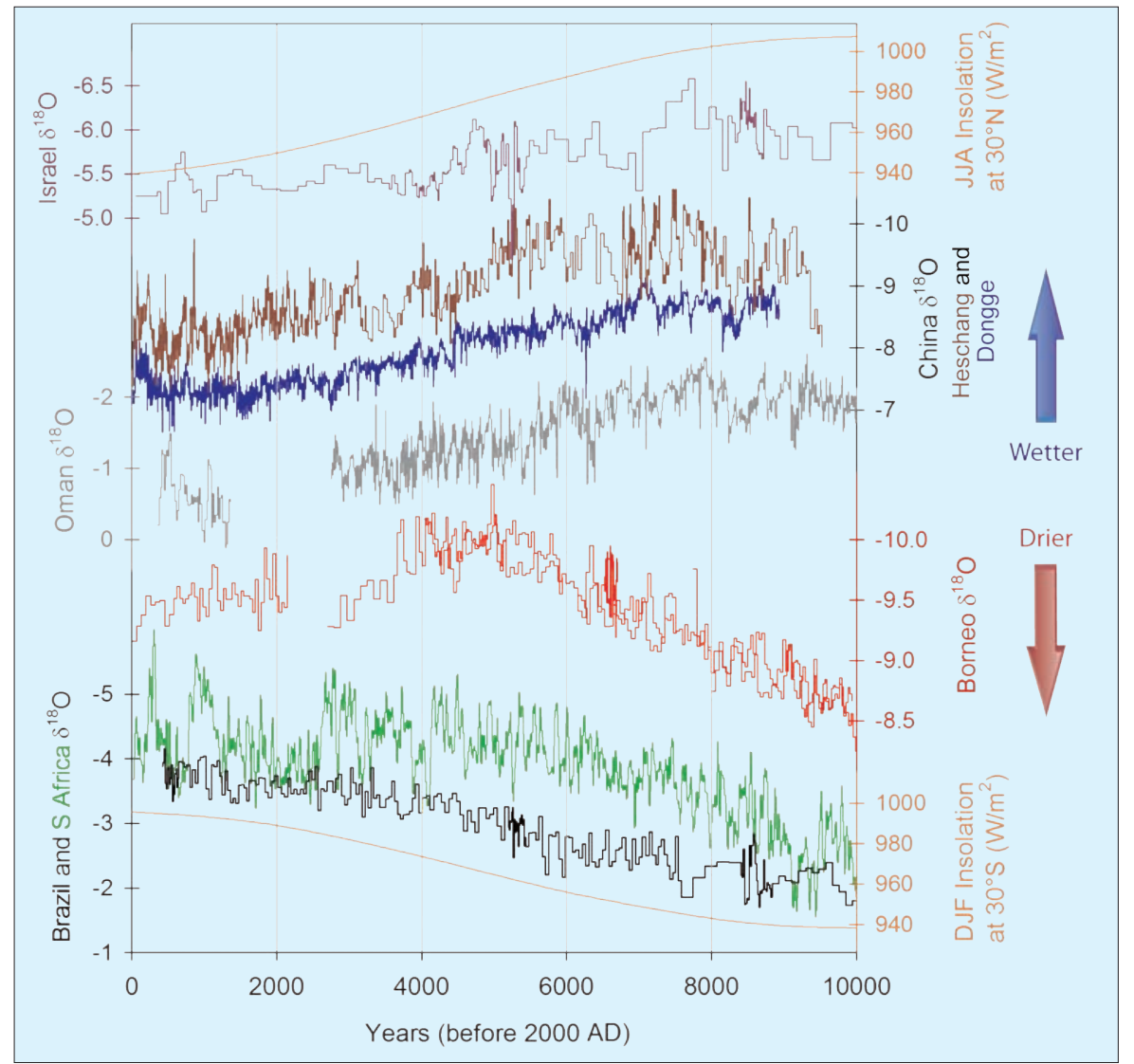

Figure 2: Speleothem $\delta^{18} \mathrm{O}$ records for the last $10 \mathrm{kyr}$ arranged from $N$ to S., Soreq Cave, Israel (purple); Heshang Cave, China (brown); Dongge Cave, China (blue); Qunf Cave, Oman (gray); Snail Shell and Bukit Assam Caves, N. Borneo (red); Cold Air Cave, S. Africa (green); Botuverá Cave, Brazil (black). Also plotted are summer insolation curves at $30^{\circ} \mathrm{N}$ (top) and $30^{\circ} \mathrm{S}$ (bottom) (orange curves). Wetter conditions correspond to smaller $8^{18} \mathrm{O}$ values and drier conditions larger $\delta^{18} \mathrm{O}$ values via the "amount effect" (note that axes are reversed).

changes in insolation, and the need for additional records from the deep tropics.

Speleothems also offer the opportunity to determine the magnitude and absolute timing of terrestrial climate changes with records that contain sub-annual- to decadal-resolution. This characteristic makes them invaluable for the study of abrupt climate change. For example, a landmark speleothem record from China links abrupt changes in the Asian Monsoon to abrupt climate changes recorded in the Greenland ice cores (Wang et al., 2001). The speleothem records from China have recently been extended to $224 \mathrm{kyr}$ at a temporal resolution of $\sim 40-70$ years (Wang et al., 2008). These extraordinary records highlight the ability of speleothems to provide climate information past MIS 5, beyond the limit of the Greenland ice cores. Speleothem records will continue to provide key constraints on the geographical extent to which abrupt climate changes affect precipitation over land.

While this article does not represent an exhaustive review of speleothem records, the small compilation of Holocene speleothem records shown in Figure 2 highlights the potential of constructing a global database of speleothem records that could be used to address a variety of paleoclimate challenges. Tree ring databases for the United States are a standard that speleothem records should try to attain; high spatial coverage at high temporal resolution over a long time period. Many authors have developed speleothem records across the globe from $100 \mathrm{kyr}$ until present, however many gaps still exist. Also needed are companion calibration studies that enhance the climatic interpretation of the stalagmite records. Speleothem records show how the hydrologic cycle is affected by external forcing, as well as how natural climate variability impacts largescale precipitation patterns. These past changes in the hydrologic cycle have important consequences for water resource planning today as they define the range that planners should consider.

\section{Note}

The websites for data from Soreq Cave (Israel), Heshang and Dongge Caves (China), Qunf Cave (Oman), Snail Shell and Bukit Assam Caves (N. Borneo), Botuverá Cave (Brazil), and Cold Air Cave (S. Africa), can be found at www.pagesigbp.org/products/newsletters/ref2008_3.html

\section{References}

Fleitmann, D., Burns, S.J., Mudelsee, M., Neff, U., Kramers, J., Mangini, A. and Matter, A., 2003: Holocene forcing of the Indian monsoon recorded in a stalagmite from Southern Oman, Science, 300: 1737-1739.

Partin, J.W., Cobb, K.M., Adkins, J.F., Clark, B. and Fernandez, D.P., 2007: Millennial-scale trends in Warm Pool hydrology since the Last Glacial Maximum, Nature, 449: 452-455.

Treble, P., Shelley, J.M.G. and Chappell, J., 2003: Comparison of high resolution sub-annual records of trace elements in a modern (1911-1992) speleothem with instrumental climate data from southwest Australia, Earth and Planetary Science Letters, 216 141-153.

Wang, X., Auler, A.S., Edwards, R.L., Cheng, H., Ito, E. and Solheid, M. 2006: Interhemispheric anti-phasing of rainfall during the last glacial period, Quaternary Science Reviews, 25: 3391-3403.

Wang, Y.J., Cheng, H., Edwards, R.L., An, Z.S., Wu, J.Y., Shen, C.C. and Dorale, J.A., 2001: A high-resolution absolute-dated Late Pleistocene monsoon record from Hulu Cave, China, Science, 294 2345-2348.

\section{Paleotemperature reconstruction using noble gas concentrations in speleothem fluid inclusions}

\section{Yvonne Scheidegger ${ }^{1,2}$, T. Kluge ${ }^{3}$, R. Kipfer ${ }^{1,2}$, W. Aeschbach-Hertig ${ }^{3}$ And R. Wieler ${ }^{1}$}

${ }^{1}$ Isotope Geochemistry and Mineral Resources, Swiss Federal Institute of Technology, ETH Zurich; yvonne.scheidegger@eawag.ch ${ }^{2}$ Water Resources and Drinking Water, Swiss Federal Institute of Aquatic Science, Eawag; ${ }^{3}$ nnstitute for Environmental Physics, University of Heidelberg, Germany.

Stalagmites are gaining importance in paleoclimate research as they provide highresolution stable isotope signals over glacial-interglacial timescales. The major difficulty in the interpretation of stalagmite oxygen and carbon isotope data is to disentangle the various effects and processes that control the signals. One important parameter is the mean air temperature in the cave. Cave temperatures remain relatively constant throughout the year at approx. the local mean air temperatures. Accordingly, paleotemperature reconstructions from cave deposits provide good estimates of the past annual mean outside the cave (McDermott, 2004; Genty et al., 2002). However, there is a lack of tools for direct determination of cave paleotemperatures. Noble gases dissolved in water inclusions can provide this informa- 